\title{
IMPLEMENTASI METODE DEMONTRASI DALAM MENINGKATKAN KEMAMPUAN KADER UNTUK STIMULASI PERTUMBUHAN DAN PERKEMBANGAN PADA ANAK
}

\section{The Use of Demonstration Methods to Improve the Ability of Cadres in Stimulating the Growth and Development of Children}

\author{
Patemah \\ Program Studi D3 Kebidanan \\ STIKES WidyagamaHusada
}

\begin{abstract}
Stimulation is the basic ability to stimulate activity of children aged 0-6 years so that children grow and develop optimally. Tujuan of this study is to analyze the methods of training for cadres to the upgrading of cadres to stimulate growth and development in children

The method is performed by pre-experiment and post-experiment. Subjects in this study were Posyandu cadres who have not received training stimulation. After treatment for 5 days using TRAINING evaluated on improving the ability of cadres to stimulate growth and development in children.

The target of this research is to find the right technique TRAINING method primarily on the mother cadres to improve the quality and quality of service on the stimulation of growth and development in children. The final results will be published in national journals and textbooks written in the form

Results of the study were mostly Posyandu cadres who were respondents in this study, before being given method of training a lot of stimulation that does not do them as much as 20 (100\%) of respondents did not undertake the implementation SDIDTK about Bring cleaning tables and menyap, and after training as many as 17 respondents (85\%) can do this stimulation. The results of the test data analysis using $t$-test $p$ value $=0.001<0.05$, which means that there are differences in the ability before training and after training.
\end{abstract}

Keywords: training, stimulation, cadre 


\section{ABSTRAK}

Stimulasi adalah kegiatan merangsang kemampuan dasar anak umur 0-6 tahun agar anak tumbuh dan berkembang secara optimal.Tujuan dari penelitian ini adalah untuk menganalisis metode Pelatihan untuk kader dengan peningkatan kemampuan kader untuk stimulasi pertumbuhan dan perkembangan pada anak

Metode yang dilakukan dengan pra eksperimen dan post eksperimen. Subjek dalam penelitian ini adalah ibu kader posyandu yang belum mendapatkan pelatihan Demontrasi stimulasi. Setelah dilakukan perlakuan selama 5 hari dengan menggunakan metode pelatihan Demontrasi dievaluasi tentang peningkatan kemampuan kader untuk stimulasi pertumbuhan dan perkembangan pada anak.

Target dari penelitian ini adalah untuk menemukan teknik metode pelatihan Demontrasi yang tepat terutama pada ibu kader guna meningkatkan mutu dan kualitas pelayanan pada stimulasi pertumbuhan dan perkembangan pada anak. Hasil akhir penelitian akan dipublikasikan pada jurnal nasional dan ditulis dalam bentuk buku ajar

Hasil penelitian sebagian besar kader posyandu yang menjadi responden dalam penelitian ini, sebelum diberikan metode Pelatihan Demontrasi banyak stimulasi yang tidak dilakukan diantaranya sebanyak 20 (100\%) responden tidak melakukan pelaksanaan SDIDTK tentang Ajak membersihkan meja dan menyap, dan setelah pelatihan sebanyak 17 responden $(85 \%)$ dapat melakukan stimulasi ini. Hasil analisa data dengan menggunakan uji T-test didapatkan nilai $\mathrm{p}=0,001 \leq 0,05$ yang berarti ada perbedaan kemampuan sebelum pelatihan dan sesudah pelatihan.

\section{Keyword: Pelatihan Demontrasi, Stimulasi, Kader}

\section{PENDAHULUAN}

Stimulasi adalah kegiatan merangsang kemampuan dasar anak umur 0-6 tahun agar anak tumbuh dan berkembang secara optimal. Kurangnya stimulasi dapat menyebabkan penyimpangan tumbuh kembang anak bahkan gangguan yang menetap. Stimulasi dini adalah rangsangan yang dilakukan sejak bayi baru lahir, dilakukan oleh ibu atau pengasuhnya dengan cara bermain, penuh kasih sayang dan suasana gembira. Anak yang mendapat stimulasi yang terarah akan lebih cepat berkembang dibandingkan anak yang kurang bahkan tidak mendapat stimulasi. Departemen (Kesehatan RI,2005)

Pemantauan perkembangan anak yang optimal dapat dilakukan dengan pembinaan tumbuh kembang anak secara komprehensif dan berkualitas yang diselenggarakan melalui kegiatan stimulasi, deteksi dan intervensi dini penyimpangan tumbuh kembang balita. Pelaksana Stimulasi di Posyandu dari masyarakat adalah kader.( Ismawati, Cahyo,2010)

Setiap kader sebagai pelaksana pekerja di Posyandu mempunyai kemampuan berdasar pada pengetahuan dan keterampilan, kompetensi yang sesuai dengan pekerjaanya, motivasi kerja dan kepuasan kerja. Keberhasilan upaya kesehatan sangat ditentukan oleh sumberdaya manusia kesehatan yang profesional. Salah satu upaya yang dapat dilakukan untuk menghasilkan dan meningkatkan sumberdaya manusia kesehatan yang profesional adalah melalui pelatihan.( Majiman, H.,2011)

Pelatihan merupakan suatu proses belajar mengajar terhadap pengetahuan dan keterampilan tertentu serta sikap agar peserta semakin terampil dan mampu melaksanakan tanggung jawabnya dengan baik sesuai standar. Kader yang mengikuti pelatihan diharapkan menjadi ujung tombak Posyandu yang tidak mengandalkan petugas kesehatan agar kader dapat secara mandiri bisa menjalankan Posyandu.( Rahayu, Budi. Buku,2005)

Demontrasi adalah metode yang digunakan pada pejgajaran manipulatif dan keterampilan, pengembangan pengertian, untuk menunjukkan bagaimana melakukan praktik-praktik baru dan memperbaiki cara 
melakukan sesuatu. (Kementrian Kesehatan Republik Indonesia,2011)

Berdasarkan hasil studi pendahuluan yang dilakukan di 3 Posyandu dengan wawancara dan observasi kepada 8 kader Posyandu didapatkan bahwa 5 kader usia di atas 45 tahun, pendidikan terakhir SLTA, lama menjadi kader di atas 10 tahun dan 3 kader berusia di bawah 45 tahun, pendidikan terakhir SLTA dan lama menjadi kader di bawah 10 tahun. Pekerjaan dari 8 kader tersebut adalah ibu rumah tangga. Petugas kesehatan yang mengikuti Posyandu rata-rata dua orang dan mereka menjalankan tugasnya melakukan kegiatan imunisasi, pengobatan dan mereka tidak sempat melihat kegiatan stimulasi yang dilakukan oleh kader. Perbedaan pelaksanaan Stimulasi antara kader yang sudah dilatih dan belum dilatih tercantum pada Tabel 1.1

Tabel 1.1. Pelaksanaan SDIDTK di Posyandu oleh Kader yang sudah dan belum dilatih Demontrasi.

\begin{tabular}{|c|c|c|c|}
\hline $\mathrm{N}$ & $\begin{array}{l}\text { Tugas } \\
\text { kader }\end{array}$ & $\begin{array}{c}\text { Sudah } \\
\text { dilatih } \\
\text { (3 orang) }\end{array}$ & $\begin{array}{c}\text { Belum } \\
\text { dilatih (5 } \\
\text { orang) }\end{array}$ \\
\hline 1 & $\begin{array}{l}\text { Melaksanan } \\
\text { Pendaftaran }\end{array}$ & $\begin{array}{l}100 \% \\
\text { benar }\end{array}$ & $\begin{array}{l}100 \% \\
\text { benar }\end{array}$ \\
\hline 2 & $\begin{array}{l}\text { Melaksanak } \\
\text { an } \\
\text { Penimbang } \\
\text { an dan } \\
\text { menuliskan } \\
\text { dalam } \\
\text { secarik } \\
\text { kertas }\end{array}$ & $\begin{array}{ll}100 \% \\
\text { benar }\end{array}$ & $\begin{array}{ll}40 & \% \\
\text { benar } & \end{array}$ \\
\hline 3 & $\begin{array}{l}\text { Pengisian } \\
\text { KMS }\end{array}$ & $\begin{array}{l}100 \% \\
\text { benar }\end{array}$ & $\begin{array}{l}40 \% \\
\text { benar }\end{array}$ \\
\hline 4 & $\begin{array}{l}\text { Memberika } \\
\mathrm{n} \\
\text { penyuluhan }\end{array}$ & $\begin{array}{l}100 \% \\
\text { melakuk } \\
\text { an }\end{array}$ & $\begin{array}{l}20 \% \\
\text { melakuk } \\
\text { an }\end{array}$ \\
\hline 5 & Pelaporan & $\begin{array}{l}100 \% \\
\text { benar }\end{array}$ & $\begin{array}{ll}60 & \% \\
\text { benar } & \end{array}$ \\
\hline
\end{tabular}

Tabel 1.1 menunjukkan kader yang sudah dilatih Demontrasi dan belum dilatih Demontrasi $100 \%$ melakukan tugasnya dengan benar, dan kader yang belum dilatih $100 \%$ benar dalam pendaftaran, $40 \%$ benar dalam melaksanakan penimbangan dan menuliskan dalam secarik kertas, 40\% benar dalam pengisian KMS, $20 \%$ benar dalam memberikan penyuluhan dan $60 \%$ benar dalam pelaporan

Berdasarkan fenomena tersebut, permasalahannya adalah bagaimana efektifitas metode pelatihan untuk meningkatkan kemampuan kader dan sejauh mana implementasi hasil pelatihan diaplikasikan untuk stimulasi pertumbuhan dan perkembangan pada anak

\section{METODE PENELITIAN} berikut:

Cara penelitiannya adalah sebagai

1. Data yang diambil langsung kader dari Puskesmas Pandanwangi untuk dijadikan responden dalam penelitian ini dan pengumpulan data dilakukan dengan menggunakan wawancara dan lembar observasi yang berisi kemampuan kader dalam stimulasi pada anak.

2. Pengukuran kemampuan kader yang dilakukan ketika kader terdaftar dalam kader aktif dan belum pernah mengikuti pelatihan stimulasi.

3. Setelah diukur kemampuannya, kemudian diberikan pelatihan tentang stimulasi pada anak selama 1 (satu) minggu di Puskesmas Pandanwangi.

4. Pengukuran kembali kemampuan kader setelah diberi metode pelatihan.

Teknik Pengolahan Data

Data yang terkumpul dilakukan: editing, coding, scoring, transfering, tabulating, selanjutnya dianalisis statistik dengan program software SPSS 16.

\section{HASIL YANG DICAPAI}

Hasil yang dicapai pada penelitian ini adalah :

1. Sebelum dilakukan perlakuan dengan metode Pelatihan Demontrasi masing masing responden di wawancara untuk mengisi lembar data demografi. Selanjutnya kader diminta untuk melakukan stimulasi pada anak saat kegiatan posyandu. Dari 20 responden, sebanyak $20(100 \%)$ responden tidak melakukan pelaksanaan SDIDTK tentang Ajak membersihkan meja dan menyapu. Sebanyak (95\%) responden 
tidak melakukan pelaksanaan SDIDTK tentang Sering memeluk dan menimang bayi dengan penuh kasih sayang, Ajari berjalan di undakan/tangga, Membuat cerita gambar tempel, Dengarkan ia ketika bercerita "ketika saya masih kecil. Sebanyak (90\%) responden tidak melakukan pelaksanaan SDIDTK tentang Perdengarkan musik pada bayi, Beri mainan benda yang besar dan berwarna, Ajari bayi duduk

2. Selanjutnya dilakukan pelatihan stimulasi selama 1 minggu.

3. Mengukur kembali kemampuan stimulasi oleh kader Dari 20 responden, menunjukkan bahwa sebanyak 9 (45\%) responden tidak melakukan pelaksanaan SDIDTK tentang beri mainan yang aman dipukul-pukul. Sebanyak (40\%) responden tidak melakukan pelaksanaan SDIDTK tentang Sering memeluk dan menimang bayi dengan penuh kasih sayang, Sering tengkurapkan bayi. Sebanyak $(35 \%)$ responden tidak melakukan pelaksanaan SDIDTK tentang Ajari memegang benda kecil dengan dua jari, Ajak bermain.

4. Pengujian dengan teknik analisa data menggunakan Hasil Uji T-test didapatkan $p=0,001 \leq 0,05$ yang berarti ada perbedaan kemampuan sebelum pelatihan dan sesudah pelatihan. Dengan demikian ada pola perbedaan bahwa kader yang belum pelatihan stimulasi kemampuannya tidak baik dan kader setelah mendapatkan pelatihan stimulasi kemampuannya baik.

Dari hasil penelitian yang telah dilaksanakan pada 20 responden, didapatkan data bahwa sebagian besar untuk kemampuan kader dalam stimulasi sebelum pelatihan yang tidak dilakukan adalah sebanyak $20(100 \%)$ responden tidak melakukan pelaksanaan SDIDTK tentang Ajak membersihkan meja dan menyapu. Sebanyak (95\%) responden tidak melakukan pelaksanaan SDIDTK tentang Sering memeluk dan menimang bayi dengan penuh kasih sayang, Ajari berjalan di undakan/tangga, Membuat cerita gambar tempel, Dengarkan ia ketika bercerita "ketika saya masih kecil. Sebanyak (90\%) responden tidak melakukan pelaksanaan SDIDTK tentang Perdengarkan musik pada bayi, Beri mainan benda yang besar dan berwarna, Ajari bayi duduk.

Setelah pelaksanaan pelatihan terjadi perubahan peningkatan kemampuan kader untuk stimulasi diantaranya sebanyak $20(100 \%)$ responden yang tidak melakukan pelaksanaan SDIDTK tentang Ajak membersihkan meja dan menyapu, terjadi perubahan $17(85 \%)$ yang melakukan stimulasi. Sebanyak (95\%) responden tidak melakukan pelaksanaan SDIDTK terjadi perubahan Sering memeluk dan menimang bayi dengan penuh kasih sayang $12(60 \%)$, Ajari berjalan di undakan/tangga 15 (75\%), Membuat cerita gambar tempel $12 \quad(60 \%)$, Dengarkan ia ketika bercerita "ketika saya masih kecil, terjadi perubahan 16 (80\%). Sebanyak (90\%) responden tidak melakukan pelaksanaan SDIDTK terjadi perubahan Perdengarkan musik pada bayi $16(80 \%)$, Beri mainan benda yang besar dan berwarna 19 (95\%), Ajari bayi duduk $16(80 \%)$

\section{PEMBAHASAN}

Pemberian stimulasi sesuai umur anak maka akan menstimulasi perkembangan kreativitas anak serta perkembangan mental dan emosional, sehingga orang tua harus mengarahkan agar sesuai dengan proses kematangan perkembangan tersebut.( Andriana, D. 2011) Kurangnya stimulasi dapat menyebabkan penyimpangan tumbuh kembang anak bahkan gangguan yang menetap. Hasil Uji T-test didapatkan $p=0,001 \leq 0,05$ yang berarti ada perbedaan kemampuan sebelum pelatihan dan sesudah pelatihan. Dengan demikian ada pola perbedaan bahwa kader yang belum pelatihan stimulasi kemampuannya tidak baik dan kader setelah mendapatkan pelatihan stimulasi kemampuannya baik. 
hal ini sesuai dengan teori bahwa Pelatihan pada hakikatnya adalah proses pembelajaran oleh karena itu untuk melatih kader dibutuhkan pengetahuan bagaimana proses belajar pada teori belajar. (Meilani, Niken,2009)

Penggunaan suatu jenis metode pembelajaran dalam pelatihan banyak ditentukan oleh tujuan mata pelajaran, keadaan kader, alat bantu belajar yang tersedia, keadaan fasilitas di dalam ruangan pelatihan. Metode yang tepat berpengaruh pada pengembangan motivasi belajar.( Yulifah, Rita,2009) Unsur-unsur yang diperhatikan dalam metode penelitian yaitu materi program pelatihan, efektivitas biaya, prinsip-prinsip pembelajaran, ketersediaan fasilitas, kecenderungan dan kemampuan peserta pelatihan dan pelatih.( Sumarsono, Sonny,2003)

\section{KESIMPULAN}

Kesimpulan dari hasil penelitian saat ini adalah dengan menggunakan metode Pelatihan Demontrasi ada perbedaan kemampuan sebelum pelatihan Demontarsi dan sesudah pelatihan Demontrasi. Dengan pola perbedaan bahwa kader yang belum pelatihan Demontrasi stimulasi kemampuannya tidak baik dan kader setelah mendapatkan pelatihan Demontrasi stimulasi kemampuannya baik

\section{DAFTAR PUSTAKA}

Departemen Kesehatan RI. Pedoman Pelaksanaan Stimulasi, Deteksi dan Intervensi Dini Tumbuh Kembang Anak, Jakarta. 2005.

Ismawati, Cahyo. Posyandu dan Desa Siaga. Bantul.PT Nufa Medika 2010.

Majiman, H. Manajemen Pelatihan Berbasis Belajar Mandiri, Yogyakarta. Pustaka Pelajar. 2011.

Andriana, D. Tumbuh Kembang dan Terapi Bermain pada Anak. Jakarta. Salemba Medika. 2011.

Rahayu, Budi. Buku Pegangan Kader . Dinas Kesehatan Propensi Jawa Timur. 2005.
Yulifah, Rita. Asuhan Kebidanan Komunitas. Jakarta. Salemba Medika 2009.

Meilani, Niken. Asuhan Kebidanan Komunitas. Yogyakarta. Fitramaja 2009.

Kementrian Kesehatan Republik Indonesia. Buku Kesehatan Ibu dan Anak. 2011.

Nursalam. Konsep dan Penerapan Metodologi Penelitian Ilmu Keperawatan. Jakarta. Salemba Medika. 2003.

Sumarsono, Sonny. Ekonomi Manajemen Sumberdaya Manusia \& Ketenagakerjaan. Yogyakarta. Graha Ilmu. 2003. 
JURNAL ILMIAH KESEHATAN MEDIAHUSADA | VOLUME 05/NOMOR 01/MARET 2016 